\title{
Characterization of the surface hydration properties of wheat flours and flour components by the measurement of contact angle
}

\author{
A. Roman-Gutierrez ${ }^{\mathrm{a}}$, J. Sabathier ${ }^{\mathrm{b}}$, S. Guilbert ${ }^{\mathrm{a}}$, L. Galet ${ }^{\mathrm{b}}$, B. Cuq ${ }^{\mathrm{a}, *}$ \\ ${ }^{a}$ Laboratoire Technologie des Céréales et des Agropolymères, ENSA-INRA Montpellier, 2 place Viala, 34060 Montpellier Cedex 1, France \\ ${ }^{\mathrm{b}}$ Laboratoire de Génie des Procédés des Solides Divisés, Ecole des Mines d'Albi-Carmaux, CNRS UMR 2392, Campus Jarlard,
}

81013 Albi Cedex 09, France

\begin{abstract}
The surface wettability properties of two wheat flours with different technological properties and of the main wheat flour components (starch, damaged starch, proteins, and soluble and insoluble pentosans) have been studied. The wettability properties were measured on compacts (produced by a classical compaction technique) by using the sessile drop method. The two selected wheat flours were characterized by relatively low values of contact angles $\left(68^{\circ}\right)$ and high rates of water drop adsorption $\left(20^{\circ} / \mathrm{s}\right)$. It was not possible to discriminate the two selected wheat flours. The flour components were characterized by highly different values of surface wettability properties. The compacts based on gluten displayed the "lowest" wettability properties, with a high initial angle $\left(85^{\circ}\right)$ and a very low rate of water drop absorption $\left(0.09^{\circ} / \mathrm{s}\right)$. The compacts based on starch and damaged starch are characterized by "high" surface wettability properties. Significant changes in physical properties (density, porosity, and microstructure) of material during compaction were considered to explain the wettability properties.
\end{abstract}

Keywords: Wheat flour; Sessile drop; Hydration; Surface properties; Contact angle; Wettability

\section{Introduction}

The study of mechanisms involved in dough formation and more particularly in the stage of flour hydration is essential to identify and control the factors that define dough properties and qualities of end products. Hydration properties of wheat flours have been mainly described from studies of water vapor sorption properties [1,2]. Differences in hydration properties of wheat flours are usually explained by differences in biochemical composition, especially with respect to the contents of damaged starch, proteins, and pentosans [3].

The physical events involved in functional properties of flours (and more particularly in hydration properties) can be described by considering the surface wettability properties. The surface energy of a solid is a good way to characterize the wettability properties [4]. The surface energy of solids

\footnotetext{
* Corresponding author. Tel.: +33-49-961-2860; fax: +33-46-7522094.

E-mail address: Cuq@ensam.inra.fr (B. Cuq).
}

determines the potential level of physical interactions that a solid is able to exchange. The knowledge of this parameter is important for the understanding and prediction of many surface and interface phenomena (e.g., adsorption, wettability, adhesion, and friction).

The surface wettability properties of powders can be estimated by the measurement of contact angles [5]. For the characterization of powders, values of contact angles have been determined by the technique of capillary rise (i.e. measurement of water penetration rates in a capillary that is filled with the powder). Contact angles are then calculated using the Washburn equation. Galet et al. [6] determined the contact angle of durum wheat semolina and water $\left(87^{\circ} \pm 2^{\circ}\right)$ using the capillary rise technique. However, water absorption by wheat semolina induced high swelling of particles and greatly limits the capillary rise of water after 1.5-2 min. The technique of capillary rise has also been used to estimate the water adsorption capacity of wheat flour [3].

The wettability properties of material can also be evaluated by the measurement of contact angle of a liquid drop 
deposited on the surface of the solid. For powders, it is necessary to carry out a preliminary stage of compaction. A water drop or water drops can then be deposited onto the upper surface of the compacts. The liquid-solid contact angle can then be measured using a protractor eyepiece on a goniometer or by photographing the drop and measuring the angle on the print. Secondary, a drop of maximum height can be produced and the measured height used to calculate a contact angle on the print $[7,8]$. However, one of the major problems in measuring the contact angle on compacts is that the process of compaction may alter the outer surface. Plastic deformation may result in a measured contact angle, which is not representative of the original powder [8]. Buckton and Newton [9] demonstrated for a number of barbiturates that an increase in compaction pressure induced an exponential decrease in contact angle until a plasticization of the compact surface occurred.

The objectives of the work were to describe the surface wettability properties of two wheat flours with different technological properties and of the main wheat flour components (starch, damaged starch, proteins, soluble, and insoluble pentosans). Compacts based on flours or flour components were first prepared by a classical compaction technique. The surface wettability properties were measured directly on compacts by using the sessile drop method. Changes in physical properties (density, porosity, and microstructure) of material during compaction were considered to describe the surface wettability properties.

\section{Materials and methods}

\subsection{Raw materials}

Commercial soft and hard wheat flours, industrial wheat gluten (Manito from Eurogerm, Dijon, France), industrial wheat starch (Roquette, Lestrem, France), water-insoluble wheat pentosans (INRA, Montpellier, France), and watersoluble wheat pentosans (CH-8033020, Leuven Bioproducts, Belgium) were used in this work. The damaged starch was obtained by grinding the wheat starch with a mortar grinder (RM 100, Fisher Scientific, France) for $30 \mathrm{~min}$. All products were stored at $4{ }^{\circ} \mathrm{C}$ in hermetic cans until needed (for maximum of 1 year). The initial contents of water, damaged starch, ash, and lipids were determined according to AACC methods (44-15, 76-31, 08-12, and 76-12) [10]. The protein contents were determined according to Dumas method (NA 2000, Fisons Instrument). The contents of water-soluble arabinoxylans and total arabinoxylans were measured by colorimetric and chromatographic methods according to Rouau and Surget [11]. Calculations were done to estimate the contents of the water-insoluble arabinoxylans (i.e. the difference between total and watersoluble arabinoxylans) and starch (i.e. difference to the other components). The biochemical composition of the wheat flours and the flour components is presented in Table 1.

Granulometric fractions of hard wheat flour were then prepared $(0-50,50-100,100-125$, and $125-160 \mu \mathrm{m})$ by hand sieving according to the French method NF XII-507 [12] using four square meshed sieves $(160,125,100$, and 50 $\mu \mathrm{m})$. The particle size distribution of wheat flours and flour fractions were determined by using laser granulometry with air drying (Granulometer Laser Masterizer 2000, Malvern, England) at room temperature. The particle size distribution is characterized by the mean diameter $\left(D_{50}\right)$ and by the dispersion $\left(D_{90}-D_{10}\right) / D_{50}$ [13]. One measurement was carried out for each product.

\subsection{Equilibration conditions}

Wheat flours and flour components were first dried in a vacuum drier at $45{ }^{\circ} \mathrm{C}$ for $12 \mathrm{~h}$. The dried particles were then equilibrated at different relative humidities (at $0 \%$ and $60 \%$ ) over saturated salt solutions for 1-2 weeks.

\subsection{Compact preparation}

Compacts (13 $\mathrm{mm}$ diameter) were prepared by pressing $0.4 \pm 0.0002 \mathrm{~g}$ of powder in a manual hydraulic press (Grasserie Specac, London, England, standard P/N 15.011) at a pressure of $700 \mathrm{MPa}$ for $1 \mathrm{~min}$ at room temperature. The compacts were immediately analyzed after preparation.

Table 1

Chemical composition of the wheat flours and flour components

\begin{tabular}{|c|c|c|c|c|c|c|c|c|}
\hline \multirow[t]{2}{*}{ Product } & \multirow{2}{*}{$\begin{array}{l}\text { Water content } \\
(\% \mathrm{db})\end{array}$} & \multicolumn{7}{|c|}{ Chemical composition $(\% \mathrm{db})$} \\
\hline & & Protein & Starch & $\begin{array}{l}\text { Damaged } \\
\text { starch }\end{array}$ & $\begin{array}{l}\text { Total } \\
\text { arabinoxylans }\end{array}$ & $\begin{array}{l}\text { Soluble } \\
\text { arabinoxylans }\end{array}$ & Ash & Lipids \\
\hline Soft wheat flour & 14.8 & 10.5 & 86.5 & 3.65 & 1.51 & 0.49 & 0.44 & 1.25 \\
\hline Hard wheat flour & 15.3 & 12.9 & 84.0 & 6.57 & 1.76 & 0.45 & 0.47 & 1.28 \\
\hline Gluten & 14.8 & 79.8 & 15.6 & 3.28 & 0.65 & 0.20 & 0.47 & 0.29 \\
\hline Starch & 14 & 0.22 & 98.9 & 1.73 & 0 & 0 & 0.12 & 0.03 \\
\hline Insoluble pentosans & 15 & 5.23 & $51.7^{\mathrm{a}}$ & 2.85 & 37.8 & 0 & 3.78 & - \\
\hline Soluble pentosans & 10.6 & - & 1.0 & 0.21 & - & 99.0 & - & - \\
\hline
\end{tabular}

$\mathrm{db}$ is defined as dry basis.

${ }^{\text {a }}$ Content of glucan molecules and resistant starches produced during preparation of samples for measurement of insoluble pentosanes. 


\subsection{Contact angle}

The wettability properties of powders were estimated by direct observation of the contact angle of a water drop (10 $\mu l)$ deposited on the surface of the compacts (Fig. 1). Freshly tapped ultrapure water was used. Measurements were carried out with a goniometer (Krüss G10) equipped with a camera (CDD, 25 images per second) and digital video tape recorder (Sony DSR-30p). Data were treated using the Krüss software 121. The initial contact angle and its change as a function of time were recorded. The apparent absorption rate of the water drop was calculated by linear regressions (in the initial linear part) of contact angles vs. time curves. For each product, average values and standard deviations were calculated from 16 measurements.

\subsection{Physical properties}

The bulk densities of dried powders and compacts (at $0 \%$ $\mathrm{RH}$ ) were determined by helium pycnometry (Accu Pyc 1330, Micrometrics, Norcross, GA) at $20{ }^{\circ} \mathrm{C}$. According to the gas displacement method, the bulk density $\left(\mathrm{g} / \mathrm{cm}^{3}\right)$ is related to the volume of product in which gas cannot penetrate. One measurement was carried out for each product.

The pore size of samples and the size distribution of pores were measured for dried powders and compacts (at $0 \%$ RH) using a mercury porosimeter (Poresizer 9310, Micromeritics Instrument). This instrument is capable of measuring very small pores $(1-8 \mathrm{~nm}$ diameter) using a maximum pressure of $408 \mathrm{MPa}(60000 \mathrm{psi})$. One measurement was carried out for each product.

The microstructure of initial dried particles and surface of compacts (at $0 \% \mathrm{RH}$ ) were characterized by using scanning electronic microscope (GSM 6300S, Joel, Japan). The powders were mounted into $13-\mathrm{mm}$ diameter aluminum stubs using double-sided adhesive tape and sputter coated with gold. The scanning electron microscope was operated with a beam accelerating potential of $12.0 \mathrm{kV}$ and images were collected in secondary electron mode.

\subsection{Mechanical properties of compacts}

The hardness of compacts (at $0 \% \mathrm{RH}$ ) was analyzed using the Hardness Erweka TBH 300 (Erweka, Milford, CT, USA).
The breaking force (newton) was measured according to the Jaw test. The friability of compacts was measured with the Friability-Abrasion Tester Erweka TAR20 (Erweka). Measurements were conducted at $30 \mathrm{rpm}$ for $15 \mathrm{~min}$ at room temperature. Five measurements were carried out for each product.

\subsection{Statistical analysis}

The statistical significance of the results was assessed using single-factor analysis of variance (ANOVA). Multiple comparisons were performed by calculating the least significant difference using the Excel Software. All tests were conducted at 5\% significance level and results are presented.

\section{Results and discussion}

The biochemical composition of wheat flours and flour components is presented in Table 1 . The principal differences between the two selected flours are the higher contents of proteins, damaged starch, and pentosans for the hard wheat flour. It is important to note that the selected fractions of flour components are not pure fractions. For instance, there is $16 \%$ starch in the gluten fraction and $52 \%$ of starch in the insoluble pentosan fraction. Nevertheless, it was considered that the functional properties of these fractions could be attributed to their major component.

The characterization of the granulometric distribution of products demonstrated that hard wheat flour particles were on average larger than soft wheat flour particles (Table 2). The average diameter $\left(D_{50}\right)$ of flour component particles are presented in Table 2. The average diameter of the starch particles $(19 \mu \mathrm{m})$ is typical for starch granules. The measured particle diameters for gluten and pentosans (82-274 $\mu \mathrm{m})$ cannot describe the characteristics of these components inside wheat flours (which are characterized by smaller sizes). Large diameters for gluten and pentosans resulted from an uncontrolled agglomeration during the purification process.

The wettability properties of wheat flours and flour components were determined by direct measurements of contact angles of a water drop deposited on the upper surface of compacts. As a typical example, the changes in contact angle as a function of time for compacts based on

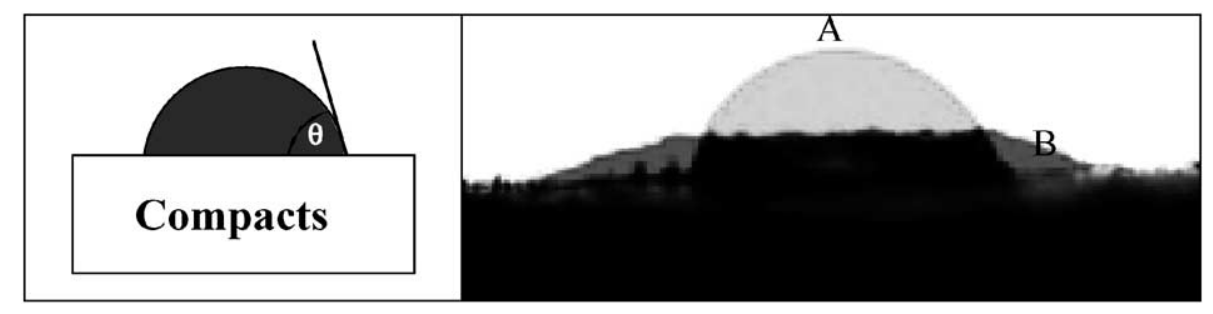

Fig. 1. Typical example for the measurements of contact angle by the method sessile drop of compact (based on hard wheat flour). The initial contact angle (A) and after $3 \mathrm{~min}(\mathrm{~B})$. 
Table 2

Physical characterization of wheat flours and flour components

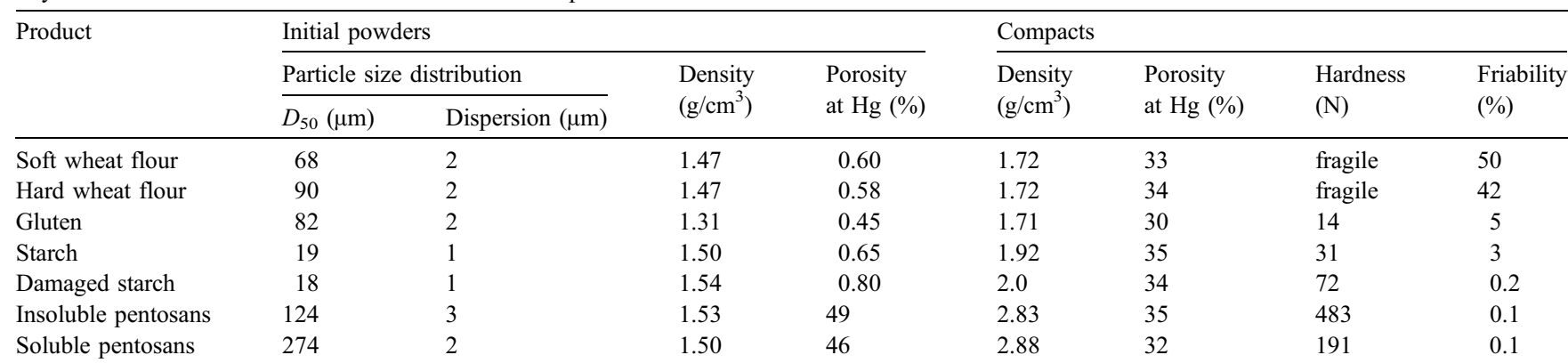

hard wheat flour are presented in Fig. 2. An initial contact angle of $68^{\circ}$ was observed for compacts equilibrated at $0 \%$ RH (Table 3). Immediately after the deposition of the water drop, we observed a rapid absorption of the water inside the compact. After few seconds, the drop was absorbed by the compact. Apparent water absorption rates were calculated from the almost linear decrease in contact angle as a function of time (Table 4). Compacts based on hard wheat flour (at $0 \% \mathrm{RH}$ ) were characterized by a relatively high value of apparent absorption rate $(21 \% \mathrm{~s})$. An increase in initial RH (from 0 to $60 \%$ ) induced a slight significant decrease in the initial value of contact angle (from $68^{\circ}$ to $58^{\circ}$ ) for hard wheat flour and also resulted in a large decrease in values of apparent absorption rate (from 21 to $14 \%$ s). As expected, increasing the initial water content of flour particles before compaction favored the initial wettability properties of the compact surface (i.e. lower initial values of contact angle), but reduced the kinetics of water drop absorption (i.e. higher absorption rates). The presence of water molecules within the compacts (before the deposition of water drop) increased the hydrophilic behavior of compact surfaces, but reduced its capability to absorb the water drop.

\section{Contact angle $\left(^{\circ}\right)$}

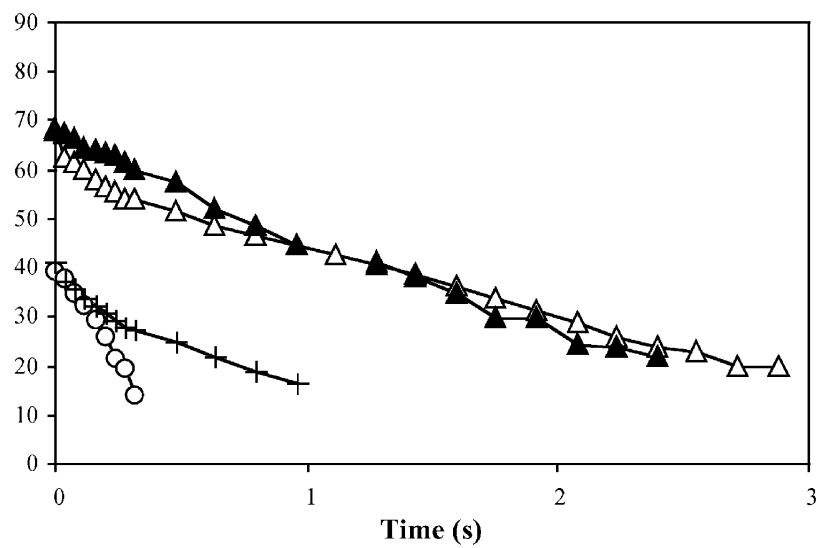

Fig. 2. Changes in contact angle of a water drop deposited on compacts based on hard wheat flour $(\boldsymbol{\Delta})$, soft wheat flour $(\triangle)$, damaged starch $(+)$, or starch $(\mathrm{O})$ (pre-equilibrated at $0 \% \mathrm{RH}$ ) as a function of time after the drop deposition.
The experimental values of initial contact angles and apparent rates of water drop absorption for compacts based on soft wheat flour are presented in Fig. 2 and Tables 3 and 4. The wettability surface properties of compacts based on soft wheat flour were close to those described for hard wheat flour (Fig. 1), with a high initial value of contact angle $\left(68^{\circ}\right)$ and low apparent absorption rate $\left(19^{\circ} /\right.$ s). It was not thus possible to significantly discriminate the hard and soft wheat flours from measurements of contact angles, although these flours were characterized by slight differences in their chemical composition (Table 1).

In order to estimate the dependence of the surface wettability properties of flours on particle diameter, we measured the contact angles of compacts based on four granulometric fractions of hard wheat flour (Table 5). The initial values of contact angle $\left(65-71^{\circ}\right)$ for compacts based on the larger fractions $\left(D_{50}>50 \mu \mathrm{m}\right)$ were not significantly different from those reported for the original flour $\left(68^{\circ}\right)$. Only the smallest fraction $\left(D_{50}<50 \mu \mathrm{m}\right)$ was characterized by a slightly lower value $\left(60^{\circ}\right)$. On the other hand, the apparent rates of water drop absorption $\left(11-13^{\circ} / \mathrm{s}\right)$ for compacts based on the larger granulometric fractions $\left(D_{50}>50 \mu \mathrm{m}\right)$ were significantly lower than those reported

Table 3

Initial values of contact angle of a water drop deposited on the surface of compacts based on wheat flours and flour components (equilibrated at different relative humidities)

\begin{tabular}{llc}
\hline Products & \multicolumn{2}{l}{ Initial values of contact angle $\left(^{\circ}\right)$} \\
\cline { 2 - 3 } & Equilibrated at $0 \% \mathrm{RH}$ & Equilibrated at $60 \% \mathrm{RH}$ \\
\hline Hard wheat flour & $68(5)^{\mathrm{b} / \alpha}$ & $58(1)^{\mathrm{b} / \beta}$ \\
Soft wheat flour & $68(7)^{\mathrm{b} / \alpha}$ & $53(1)^{\mathrm{c} / \beta}$ \\
Gluten & $85(4)^{\mathrm{a} / \alpha}$ & $67(2)^{\mathrm{a} / \beta}$ \\
Starch & $38(4)^{\mathrm{d} / \alpha}$ & $30(1)^{\mathrm{d} / \beta}$ \\
Damaged starch & $41(2)^{\mathrm{c} /-}$ & - \\
Insoluble pentosans & $41(2)^{\mathrm{c} / \beta}$ & $65(1)^{\mathrm{a} / \alpha}$ \\
Soluble pentosans & $38(3)^{\mathrm{d} /-}$ & - \\
\hline
\end{tabular}

Values inside parentheses are standard deviations.

Analysis of variance (using the Excel software) was conducted to evaluate the significant differences between average values. Comparison of products (i.e. same column) was done with different letters (a, b, c, d) when significantly different (at $p<0.05$ ). Comparison of equilibration conditions (i.e. same lines) was done with different Greek letters $(\alpha, \beta)$ when significantly different $(p<0.05)$. 
Table 4

Apparent rates of water drop adsorption by compacts based on wheat flours and flour components (equilibrated at different relative humidities)

\begin{tabular}{llc}
\hline Products & \multicolumn{2}{c}{ Rate of water drop absorption $(\% / \mathrm{s})$} \\
\cline { 2 - 3 } & Equilibrated at $0 \% \mathrm{RH}$ & Equilibrated at $60 \% \mathrm{RH}$ \\
\hline Hard wheat flour & $21(2)^{\mathrm{b} / \alpha}$ & $14(2)^{\mathrm{b} / \beta}$ \\
Soft wheat flour & $19(2)^{\mathrm{b} / \alpha}$ & $15(1)^{\mathrm{b} / \beta}$ \\
Gluten & $0.09(0.01)^{\mathrm{d} / \alpha}$ & $0.07(0.01)^{\mathrm{d} / \beta}$ \\
Starch & $87(16)^{\mathrm{a} / \alpha}$ & $34(5)^{\mathrm{a} / \beta}$ \\
Damaged starch & $22(2)^{\mathrm{b} /}$ & - \\
Insoluble pentosans & $1.3(0.1)^{\mathrm{c} / \alpha}$ & $1.4(0.2)^{\mathrm{c} / \alpha}$ \\
Soluble pentosans & $0.07(0.01)^{\mathrm{e} /-}$ & -
\end{tabular}

Values inside parentheses are standard deviations.

Analysis of variance (using the Excel software) was conducted to evaluate the significant differences between average values. Comparison of products (i.e. same column) was done with different letters (a, b, c, d, e) when significantly different (at $p<0.05$ ). Comparison of equilibration conditions (i.e. same lines) was done with different Greek letters $(\alpha, \beta)$ when significantly different $(p<0.05)$.

for the initial flour $(21 \%)$. The apparent absorption rate $(23 \%)$ of the smallest fraction $\left(D_{50}<50 \mu \mathrm{m}\right)$ seemed to greatly contribute to the flour properties.

The surface wettability properties of the flour components were presented in Figs. 2 and 3. The flour components were characterized by significantly different values of wettability (Tables 3 and 4). The compacts based on starch (at $0 \% \mathrm{RH}$ ) were characterized by a low initial value of contact angle $\left(38^{\circ}\right)$. This low value means that compacts based on starch exhibit "good" surface wettability properties. The high apparent rate of water drop absorption $\left(87^{\circ} / \mathrm{s}\right)$ is associated with a very short time for water drop absorption inside the compact $(<1 \mathrm{~s})$. The hydrophilic structure of starch molecules [14] could explain the high surface wettability properties of starch-based compacts. It should be noticed that Liukkonen [15] found a similar value of contact angle for starch by measuring the contact angle of a microdrop of water directly deposited on the surface of one

Table 5

Physical characteristics of the granulometric fractions of hand-sieved hard wheat flour (equilibrated at $0 \% \mathrm{RH}$ )

\begin{tabular}{|c|c|c|c|c|c|}
\hline \multirow[t]{3}{*}{ Fractions } & \multicolumn{2}{|l|}{ Compacts } & \multicolumn{3}{|c|}{ Particles } \\
\hline & \multirow[t]{2}{*}{$\begin{array}{l}\text { Contact } \\
\text { angle }\left({ }^{\circ}\right)\end{array}$} & \multirow{2}{*}{$\begin{array}{l}\text { Rate of } \\
\text { water drop } \\
\text { absorption } \\
(\% / s)\end{array}$} & \multicolumn{2}{|c|}{$\begin{array}{l}\text { Particle size } \\
\text { distribution }\end{array}$} & \multirow[t]{2}{*}{$\begin{array}{l}\text { Density } \\
\left(\mathrm{g} / \mathrm{cm}^{3}\right)\end{array}$} \\
\hline & & & $\begin{array}{l}D_{50} \\
(\mu \mathrm{m})\end{array}$ & $\begin{array}{l}\text { Dispersion } \\
(\mu \mathrm{m})\end{array}$ & \\
\hline Hard wheat & $68(5)^{\mathrm{ab}}$ & $21(1)^{\mathrm{a}}$ & 90 & 1.87 & 1.468 \\
\hline $125-160 \mu \mathrm{m}$ & $67(1)^{\mathrm{ab}}$ & $11(2)^{b}$ & 156 & 1.72 & 1.469 \\
\hline $100-125 \mu \mathrm{m}$ & $65(1)^{b}$ & $11(2)^{b}$ & 119 & 1.87 & 1.469 \\
\hline $50-100 \mu \mathrm{m}$ & $71(1)^{\mathrm{a}}$ & $13(1)^{b}$ & 92 & 1.57 & 1.468 \\
\hline $0-50 \mu \mathrm{m}$ & $60(1)^{c}$ & $23(2)^{\mathrm{a}}$ & 30 & 1.78 & 1.476 \\
\hline
\end{tabular}

Values inside parentheses are standard deviations.

Analysis of variance (using the Excel software) was conducted to evaluate the significant differences between average values. Comparison of products (i.e. same column) was done with different letters $(a, b, c)$ when significantly different (at $p<0.05$ ).
Contact angle $\left(^{\circ}\right)$

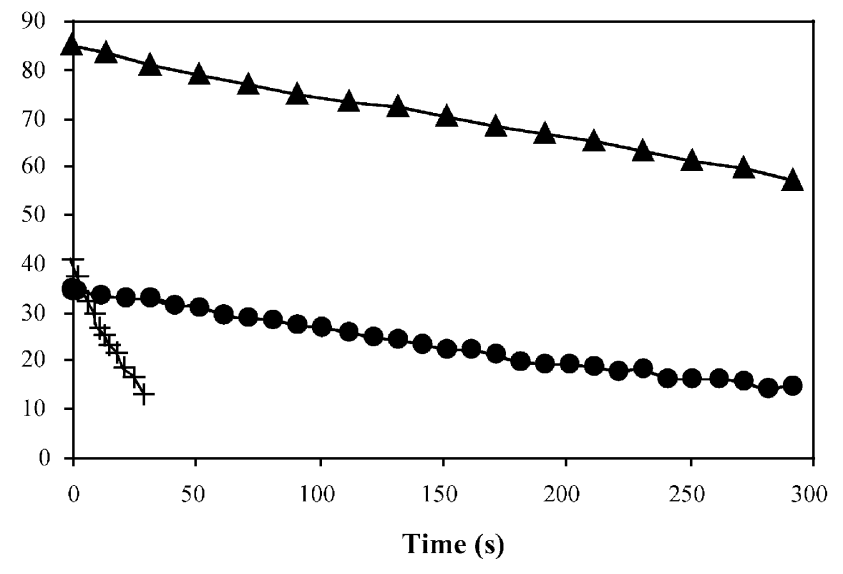

Fig. 3. Changes in contact angle of a water drop deposited on compacts based on wheat gluten $(\boldsymbol{\Delta})$, insoluble pentosans $(+)$, or soluble pentosans (•) (pre-equilibrated at $0 \% \mathrm{RH}$ ) as a function of time after the drop deposition.

particle using environmental scanning electron microscope. An increase in initial RH conditions (from $0 \%$ to $60 \%$ ) resulted in a slight significant decrease in initial value of contact angle (from $38^{\circ}$ to $30^{\circ}$ ) and in apparent rate of water drop absorption (from $87^{\circ} / \mathrm{s}$ to $34 \%$ ). As expected, the initial hydration of starch compacts favored the initial wettability properties, but reduced the absorption rate. The initial value of contact angle for damaged starch was not significantly different from that of starch (Table 3 ). On the other hand, a lower apparent rate of water drop absorption $\left(22^{\circ} / \mathrm{s}\right)$ for damaged starch when compared to starch was reported (Table 4).

The surface wettability properties of the other flour components (gluten, insoluble, and soluble pentosans) were also determined (Fig. 3). In comparison with the properties of flours and starches, the time necessary for absorption of the water drop by these compacts is longer (between 25 and $400 \mathrm{~s}$ ). The compacts based on gluten (at $0 \% \mathrm{RH}$ ) were characterized by "poor" surface wettability properties (Tables 3 and 4$)$, with a very high initial contact angle $\left(85^{\circ}\right)$ and low apparent rate of water drop absorption $\left(0.09^{\circ} / \mathrm{s}\right)$. The water drop did not spread over the surface of the glutenbased compact and seemed to remain "intact" for several minutes. These "poor" wettability properties of glutenbased compacts could be associated with its partially hydrophobic nature [14]. An increase in the initial water content of gluten due to an increase in initial RH (from $0 \%$ to $60 \%$ ) resulted in an expected slight reduction in the values of initial contact angle (from $85^{\circ}$ to $67^{\circ}$ ) and in apparent rate of water drop absorption (from $0.09^{\circ} / \mathrm{s}$ to $0.07^{\circ} / \mathrm{s}$ ).

For the soluble and insoluble pentosans (at $0 \% \mathrm{RH}$ ), the initial values of contact angles (Table 3 ) were not significantly different $\left(38^{\circ}\right.$ and $\left.40^{\circ}\right)$. These values were close to those previously measured for the starch-based compacts (Table 3) and described high surface wettability properties. These properties of pentosans are in agreement with the 
high water absorption properties that are classically observed for these components [16]. It should be noted that compacts based on pentosans are characterized by a very low rate of water drop absorption $(0.07-1.3 \%$ s), which could be due to modifications of the compact surface during the powder compaction. These modifications could explain the unexpected effect (i.e. increase in initial value of contact angle) of an increase in initial RH for insoluble pentosans on their wettability properties (Tables 3 and 4).

The initial values of contact angle measured for compacts based on wheat flours are located in between those measured for gluten and for other flour components (starch and pentosans) (Table 3). The contribution of each component to the surface wettability behavior of the wheat flours depends on the surface repartition of flour components. We could suppose a given structural organization of components on the surface of flour particles, which involve mainly the repartition of gluten protein. Changes in particle properties during compaction can also affect the surface particles.

The measurement of surface wettability properties of wheat flours and flour components was carried out by an indirect method. Indeed, it was not possible to directly measure the contact angles of water drops on powdered materials. The determination of contact angles on the upper surface of compacts was firstly considered to describe the properties of particles. However, we have to consider possible structural changes of flours and flour components that could occur during the compaction. The physical properties of particles and compacts were thus characterized in order to estimate the possible structural changes induced by the compaction process (Table 2).

The density of particles and compacts was measured by helium pycnometry (Table 2). The particles of hard and soft wheat flours were characterized by similar values of density $\left(1.47 \mathrm{~g} / \mathrm{cm}^{3}\right)$. These values of density are in the classical range $\left(1.3-1.5 \mathrm{~g} / \mathrm{cm}^{3}\right)$ for cereal flours [17]. The density of flour components was found between $1.31 \mathrm{~g} / \mathrm{cm}^{3}$ (for gluten) and $1.54 \mathrm{~g} / \mathrm{cm}^{3}$ (for pentosans). Considering the content and density of components, the theoretical density of flours was calculated $\left(1.48 \mathrm{~g} / \mathrm{cm}^{3}\right)$ and was close to the measured values $\left(1.47 \mathrm{~g} / \mathrm{cm}^{3}\right)$. Therefore, the densities of flour particles thus depend on the contribution of each component. The densities of compacts were significantly higher than those measured for particles (Table 2). The densities of materials in compacts ranged between 1.7 and $2.9 \mathrm{~g} / \mathrm{cm}^{3}$. As expected, the compaction of particles induced thus a significant increase in density. The Cam Clay model describes the relationship between the changes in density of powdered material during compaction and the pressure of compaction [18]. During compaction under low pressures, deformations of particles are elastic and reversible. During compaction under high pressures, deformations of particles are plastic and irreversible. It is known that starch presents a plastic deformation during compres-

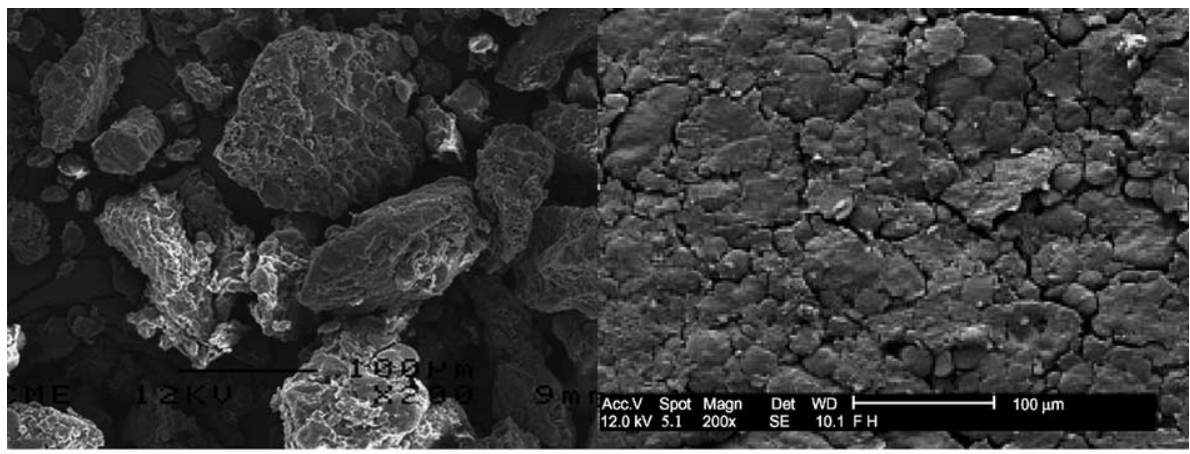

Hard wheat flour

Compact based on hard wheat flour

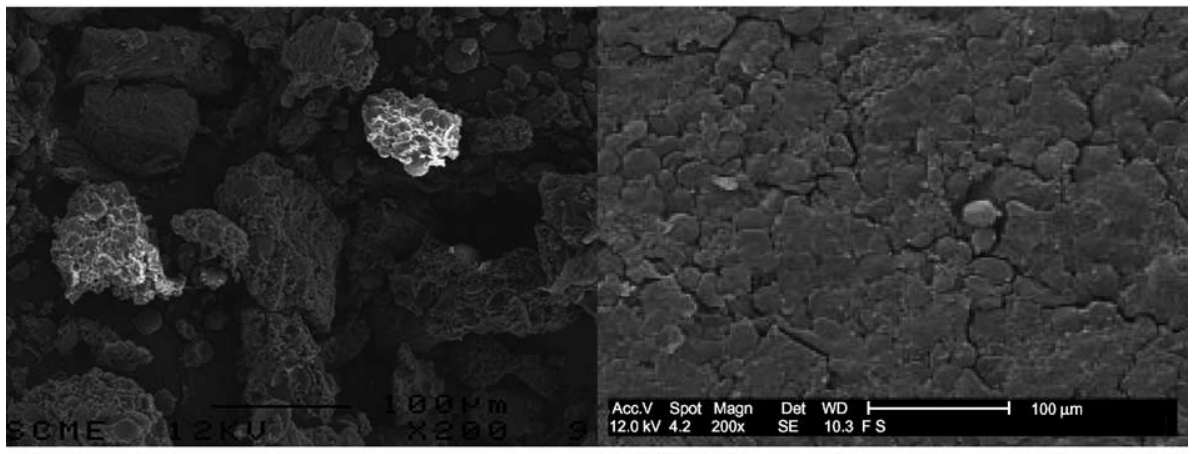

Soft wheat flour

Compact based on soft wheat flour

Fig. 4. Microstructural characterization by scanning electron microscopy of powders and compacts based on hard wheat flour and soft wheat flour (equilibrated at $0 \% \mathrm{RH})$. 
sion [19]. Serris et al. [20] evaluated for starch the critical compaction pressure at $300 \mathrm{MPa}$ before viscoplastic deformations. This value is lower than the pressure applied during our experiments $(700 \mathrm{MPa})$ for the compaction of wheat flours and flour components. The compaction process is thus responsible of the observed increase in material density.

For the determination of wettability properties of powders by the measurements of contact angle on compacts, we also have to consider the porosity of the material. The measured values of porosity for initial particles (Table 2) are typical of nonporous particles (porosity $<0.8 \%$ ), except for pentosans (porosity $=46-49 \%$ ). Wheat flour, gluten, and starch particles did not present any intra-particular porosity. The high values of porosity measured for the pentosan particles can be explained by a specific structural organization (i.e. a porous fibrous structure) of pentosan molecules (Fig. 6). Porosity at mercury was also measured for the compacts based on wheat flour or flour components (Table 2). A real inter-particular porosity was observed for the compacts, with values ranging from $30 \%$ to $35 \%$. Compaction of flour particles did not permit to obtain homogenous compact without a high inter-particular porosity. Even if the compaction pressure was very high $(700 \mathrm{MPa})$ and induced a densification of particles, the compaction conditions did not permit to ensure a perfect agglomeration of particles (i.e. without inter-granular porosity). The presence of intergranular porosity in compacts significantly affects the kinetic parameters (i.e. apparent rates of water drop absorption) $[18,21]$.

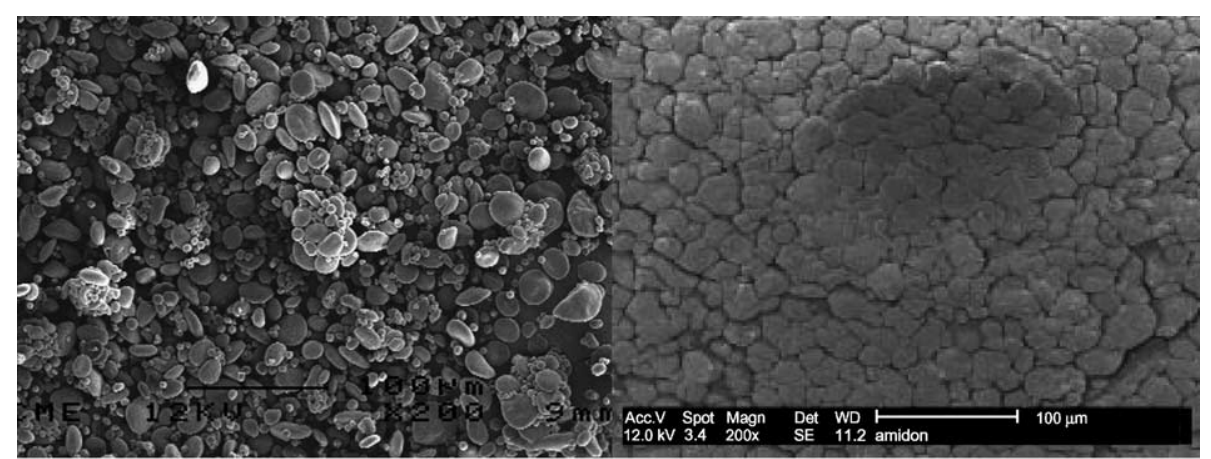

Wheat starch

Compact based on wheat starch

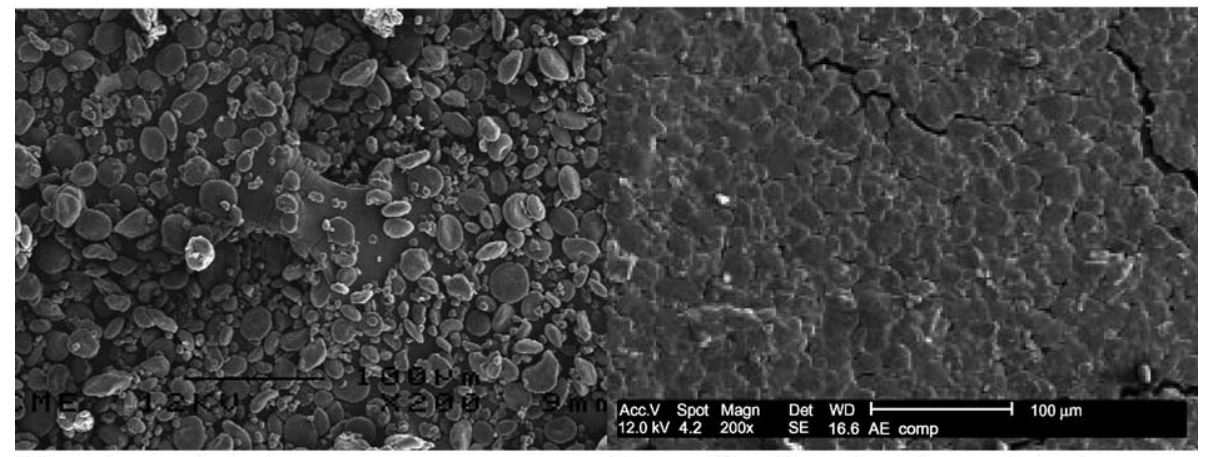

Wheat damaged starch

Compact based on wheat damaged starch

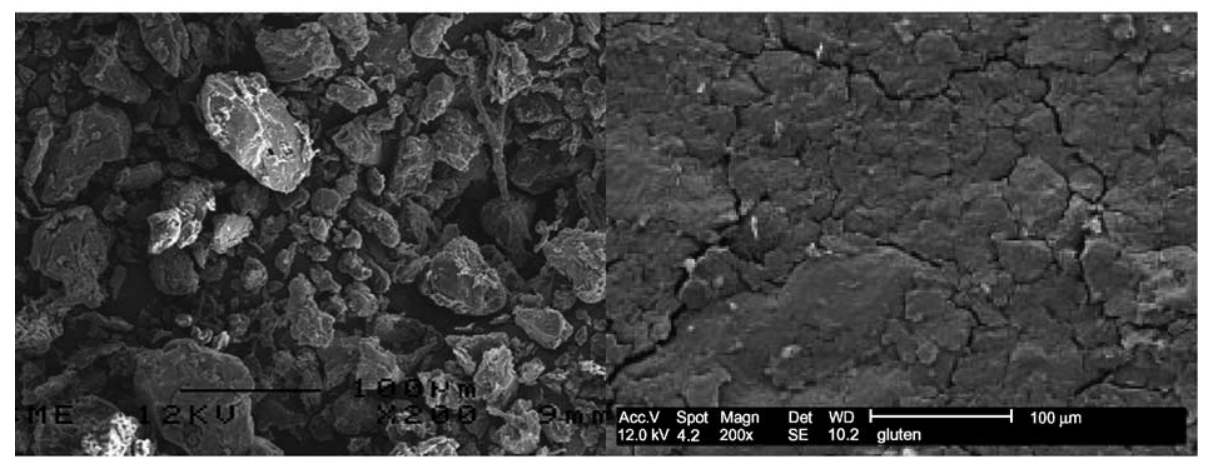

Wheat gluten

Compact based on wheat gluten

Fig. 5. Microstructural characterization by scanning electron microscopy of powders and compacts based on the wheat starch, damaged starch, or gluten (equilibrated at $0 \% \mathrm{RH}$ ). 
In order to get a better description of the compact structure, the compact surface was observed by scanning electronic microscopy and compared to the initial structure of particles (Figs. 4-6). Compacts based on wheat flour were characterized by a relatively "poor" adhesion between particles (which were still observable) and by the presence of a large number of holes and crackings (Fig. 4). The low adhesion of flour particles inside compacts permits the formation of inter-granular porosity (Table 2) and can also be considered responsible in the "poor" mechanical properties of these compacts (Table 2). Wheat flour-based compacts were characterized by high friability and are fragile.

For the compacts based on wheat gluten, we observed a relatively fine adhesion of the initial particles (Fig. 4), with an apparent "melting" of some particles. Starch-based compacts were characterized by an apparent fine adhesion between the initial particles (Fig. 5). Holes and crackings are still observable on the surface of compacts based on starch or gluten. Low values of hardness (14-72 N) and very low values of friability $(0-5 \%)$ characterized the fine adhesion between particles that formed these compacts (Table 2). For the compacts based on pentosans, we observed a very organized structure with strong interactions between the initial particles (Fig. 6). It was then not possible to discriminate the initial structure on the surface of compacts. This structure was responsible in high mechanical properties of compacts (Table 2). It should be noticed that some holes and crackings are still observable (Fig. 6).

The microstructure description of the compact surfaces thus confirmed the presence of inter-particular porosity inside compacts, due to a "poor" adhesion between particles or to the presence of holes and crackings (except for pentosan compacts). The kinetic parameters of the wettability properties depend on two phenomena: (1) water diffusion inside particles and (2) water absorption in the intergranular porosity. It was thus not possible to discriminate the contribution of each phenomenon.

\section{Conclusion}

The results obtained in this paper demonstrated that the measurements of contact angle of water drop deposited on the surface of compact give relevant values of wettability properties for cereal-based powders. Initial values of contact angles were considered to evaluate the contribution of wheat components to the surface properties of wheat flours. The determination of physical properties of compacts (i.e. density, porosity, and microstructure) demonstrated that physical changes occurred during the preparation of compacts (i.e. increase in density and porosity), and partly affected the values of apparent rate of water drop adsorption. A complementary approach to describe the dynamic changes in surface

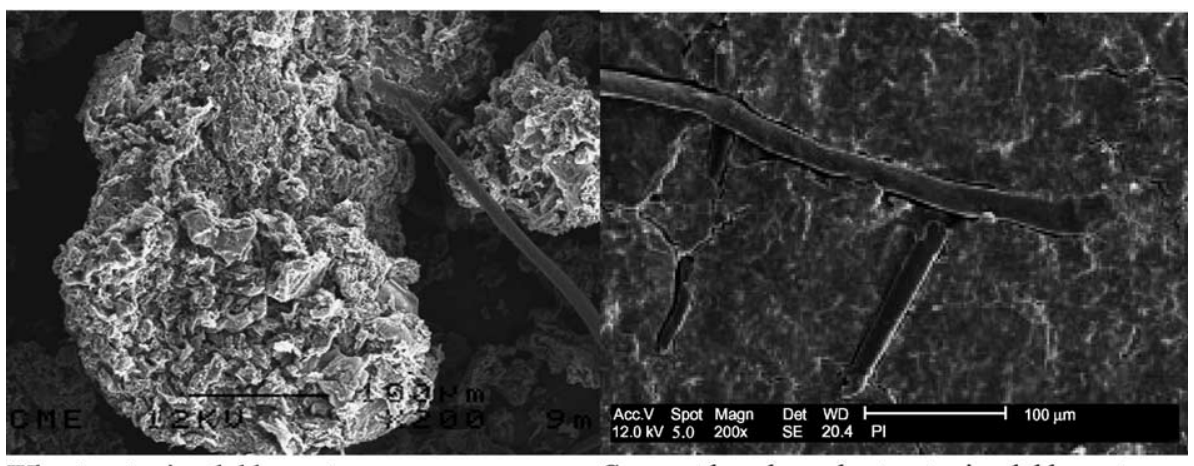

Wheat water-insoluble pentosans

Compact based on wheat water-insoluble pentosans

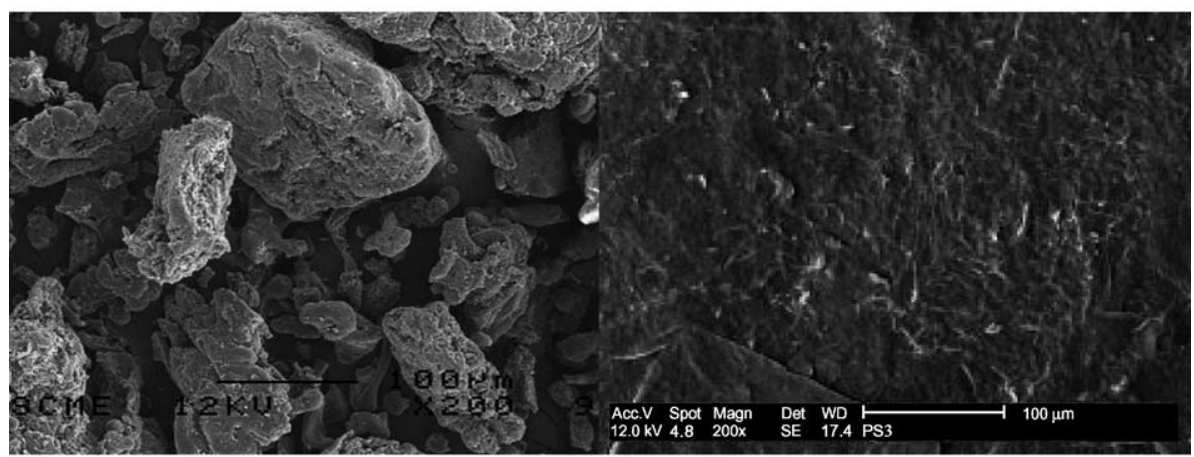

Wheat water-soluble pentosans

Compact based on wheat water-soluble pentosans

Fig. 6. Microstructural characterization by scanning electron microscopy of powders and compacts based on insoluble pentosans and soluble pentosans (equilibrated at $0 \% \mathrm{RH}$ ). 
wettability properties of cereal-based powders would be considered by using a microanalysis technique based on measurements with an environmental SEM of contact angles of a water microdrop, directly deposited on one particle [15].

\section{Acknowledgements}

The authors acknowledge financial support from CONACyT (Consejo Nacional de Ciencia y Tecnologia) of Mexico (Doctorate bourse 72743).

\section{References}

[1] A.M.R. Pilosof, R. Boquet, G.B. Bartholomai, J. Food Sci. 50 (1985) 278.

[2] J. Potus, R. Drapon, L. Rakotozafy, Ind. Céréales 79 (1992) 13.

[3] B. Berton, J. Scher, J. Hardy, F. Villieras, Récent. Prog. en Génie Procédés 15 (2001) 97.

[4] G. Buckton, J.M. Newton, J. Pharm. Pharmacol. 37 (1985) 605.

[5] H. Lechner, Eur. Coat. J. 9 (1997) 799.
[6] L. Galet, D. Fernández, D. Oulahna, J. Fages, Récent. Prog. en Génie Procédés 13 (1999) 69.

[7] G. Buckton, Powder Technol. 61 (1990) 237.

[8] G. Buckton, J. Adhes. Sci. Technol. 7 (1993) 205.

[9] G. Buckton, J.M. Newton, Powder Technol. 46 (1986) 201.

[10] American Association of Cereal Chemists, Approved Methods of the AACC, 9th ed., MN, USA, 1998.

[11] X. Rouau, A. Surget, Carbohydr. Polym. 24 (1994) 123.

[12] Association Française de Normalisation, 3rd ed., Paris, France, 1987.

[13] T. Allen, Particle size measurement, Powder Technology Series, Chapman \& Hall (Ed.), Portland, OR, 1990, p. 146.

[14] E.N. Greer, B.A. Stewart, J. Sci. Food Agric. 10 (1959) 248.

[15] A. Liukkonen, Scanning 19 (1997) 411.

[16] A.M. Cadden, J. Food Sci. 53 (1988) 1150.

[17] J.P. Melcion, Les industries de première transformation des céréales, Lavoisier (Ed.), Paris, 1991, p. 157.

[18] J. Baco-Carles, D. Lemaitre, P. Poquillon, J. Tailhades, A. Lacaze, Récent. Progrés en Génie Procédés 15 (2001) 397.

[19] G.K. Bohuis, Z.T. Chowhan, Pharm. Powder Compaction Technol., Drugs Pharm. Sci. 71 (1996) 419.

[20] E. Serris, L. Perier-Camby, G. Thomas, M. Desfontaines, G. Fantozzi, Récent. Progrés en Génie Procédés 15 (2001) 385.

[21] K.C. Link, E.U. Schlünder, Chem. Eng. Technol. 19 (1996) 432. 